\title{
Alguns Traços de Análise de Três Gerações de Planos Nacionais de Acção para a Inclusão
}

\begin{abstract}
"A exclusão social é simultaneamente um fenómeno do passado e do presente e, se não for solucionado, pertencerá também ao futuro. Recai sobre milhões de pessoas que tentam sobreviver nas mais duras condições de vida e de trabalho".
\end{abstract}

(Estivill, Jordi, 2003, Panorama de luta contra a exclusão social, Espanha, BIT/STEP, P.v.)

\begin{abstract}
$\mathrm{R}$ O artigo Alguns Traços de Analise de Três Geraçoes de Planos Nacionais de Acção para a Inclusão, sem pretensão de abordar toda a complexidade de dimensões possível, propõe-se realizar uma breve análise de três gerações de Planos Nacionais de Acção para a Inclusão, instrumentos de planeamento cujo objectivo central é o combate à pobreza e à exclusão social e que se vêm integrando no processo europeu de inclusão social. Assim, inicia com uma referência ao contexto europeu, destacando as principais orientações para esta área; traça uma breve panorâmica dos desafios enunciados por alguns dos indicadores de pobreza, que motivam a necessidade de Estratégias de Inclusão, para em seguida, centrar a análise dos PNAI em três dimensões globais: processos, actores e domínios de política; passando depois por uma reflexão sobre a monitorização/acompanhamento e avaliação e terminando com algumas reflexões em termos de síntese final.
\end{abstract}

Palavras-chave: Pobreza e Exclusão Social; Diagnóstico; Planos de Inclusão; Monitorização e Avaliação.

\section{Introdução}

O presente artigo propõe uma breve perspectiva analítica em torno de três gerações de Planos Nacionais de Acção para a Inclusão, tidos como instrumentos de planeamento que privilegiam o combate à pobreza e à exclusão social e que se vêm integrando no processo europeu de inclusão social. Parte duma referência europeia - a Estratégia de Lisboa - e passa em revista algumas das questões que se colocam ao que se convencionou chamar processo europeu de inclusão social.

Propõe-se ainda uma breve panorâmica sobre alguns dos indicadores de pobreza que motivam a necessidade dos Planos, com especial enfoque no caso português.
$\mathrm{O}$ breve enquadramento europeu, que em seguida se traça, deixa entrever um "ideal social" de erradicação da pobreza e da exclusão social numa UE (hoje a 27) e na qual a coesão social se apresenta ainda como uma espécie de utopia (realizável?). Na realidade, pode dizer-se que boa parte das políticas sociais perseguem esse ideal que, apesar de assentar claramente numa intencionalidade das acções, dificilmente prevê todos os seus impactos sobre as experiências vividas, sobretudo pelos mais desfavorecidos e/ou excluídos. Uma das dificuldades desta "previsão" reside eventualmente na fragilidade dos processos de monitorização e avaliação das políticas sociais e na difícil tarefa de medição dos seus impactos.

\footnotetext{
* Socióloga - Técnica Superior Principal do Instituto da Segurança Social, I. P. Contacto: alda.m.goncalves@seg-social.pt
} 
$\mathrm{O}$ caso português revela alguns traços de fragilidade e traços de potencialidade em todas as fases e nas três gerações de Planos até ao momento efectuados (o primeiro dos quais esteve em vigor de 2001 a 2003 , o $2 .^{\circ}$ entre 2003 e 2005 , com uma actualização para 2005-2006 e o 3. ${ }^{\circ}$ está em vigor desde Setembro de 2006 até 2008).

O presente artigo permite, pois, uma panorâmica breve das principais orientações europeias para esta área, para se debruçar particularmente sobre as legibilidades técnico-políticas de tais orientações, expressas depois em orientações e práticas nacionais, pela monitorização e avaliação, terminando com algumas ideias ou reflexões de síntese final.

\section{Combate à pobreza e à exclusão social: breve enquadramento europeu}

\section{A Estratégia de Lisboa e o processo europeu de inclusão social}

As sociedades actuais encontram-se em constantes mutações, com traços característicos diversos, desde as alterações demográficas, familiares, sociais e económicas aos crescentes progressos tecnológicos globais e à intensificação da concorrência internacional. Contudo, nelas se continuam a inscrever problemas estruturais que demonstram a importância de reforçar o papel do combate à pobreza e à exclusão social, assim como o da inclusão no programa estratégico da União Europeia e de cada um dos respectivos Estados-Membros.

Pode dizer-se que "a Cimeira de Lisboa (Março de 2000) constituiu um marco fundamental no qual os Chefes de Estado e de Governo dos Estados-Membros assumiram o objectivo estratégico de tornar a Europa comunitária no espaço baseado na economia do conhecimento mais competitiva do mundo, promovendo mais e melhores empregos $e$ mais coesão social. Neste contexto, foi assumido o compromisso de produzir um impacto decisivo na erradicação da pobreza e da exclusão social"1, até 2010. A partir desta cimeira preconizava-se a implementação da designada Estratégia de Lisboa.

Neste contexto, foi proposto o Método Aberto de Coordenação (MAC), como o principal vector político para alcançar tal objectivo e esta estratégia de cooperação no domínio da protecção e da inclusão social, isto é, na promoção de políticas inclusivas e de combate à pobreza e exclusão social.

O MAC é suportado por Objectivos Comuns ${ }^{2}$, consensuais a todos os Estados-Membros, por metas ambiciosas mas realistas para os alcançar e em torno dos quais são elaborados os PNAI, nos quais os Estados-Membros apresentam as soluções e/ou políticas que se propõem implementar; Indicadores Comuns, simultaneamente de suporte aos diagnósticos dos problemas e à monitorização e avaliação dos objectivos e das metas a alcançar; Relatórios Conjuntos de avaliação dos Planos, elaborados pela Comissão Europeia e que permitem um retrato quer dos problemas de pobreza e exclusão social na União Europeia, quer uma síntese das principais abordagens estratégicas que os diversos países se propõem adoptar para “produzir um impacto decisivo na erradicação da pobreza e da exclusão social", quer ainda as principais potencialidades e fragilidades do PNAI de cada país.

Para responder às actividades necessárias à implementação do MAC, foi criado o Programa Comunitário de Acção Contra a Exclusão Social (em 2002), com o objectivo de garantir a cooperação entre os Estados-Membros através:

i) da promoção de uma melhor compreensão sobre a pobreza e a exclusão social, nomeadamente com a ajuda de indicadores comparativos;

iii) da organização de trocas de experiências sobre as medidas de política e aprendizagens no contexto dos PNAI.

iii) Do desenvolvimento da capacidade dos actores de efectuarem abordagens eficazes sobre a pobreza e a exclusão social, promovendo perspectivas inovadoras e favorecendo particularmente o trabalho em rede e o diálogo entre todos os actores relevantes no combate à pobreza e à exclusão social.

\footnotetext{
${ }^{1}$ In Plano Nacional de Acção para a Inclusão, 2006-2008, MTSS, Setembro, 2006, p. 3.

2 No Conselho Europeu de Nice (Out. 2000), foram fixados os seguintes Objectivos Comuns de Inclusão Social: 1. Promover a participação no emprego e o acesso de todos os recursos, aos direitos, aos bens e serviços; 2. Prevenir os riscos de exclusão; 3 . Actuar em favor dos mais vulneráveis e 4. Mobilizar o conjunto dos intervenientes. As primeiras duas gerações de Planos (2001-2003 e 2003-2005), assim como o Relatório de Actualização 2005-2006 foram elaborados em torno destes objectivos que sofreram alterações em 2006.
} 
No início de 2005, as dificuldades reveladas pela conjuntura económica internacional e comunitária, levaram à revisão das metas fixadas no âmbito da Estratégia de Lisboa, centrando-a na importância do crescimento económico e do emprego, embora reafirmando a importância da inclusão social, reforçando algumas dimensões da sua governação e propondo maior simplificação e transparência de procedimentos. Neste contexto foram também revistos o MAC e a Agenda Social Europeia.

A Agenda Social Europeia ${ }^{3}$ revista (em 2005) veio incidir na importância de reforçar a confiança dos cidadãos para, de forma mais eficaz, enfrentar os grandes desafios que se colocam aos níveis do desemprego, da persistência da pobreza e das desigualdades, nomeadamente através da modernização das políticas sociais.

Por seu lado, a revisão do Método Aberto de Coordenação ${ }^{4}$ conduziu à sua racionalização (perspectiva designada por "streamlining") e surgiu em resposta aos sucessivos apelos do Conselho Europeu no sentido de empreender uma maior simplificação, integração e coerência dos processos de coordenação existentes em termos de inclusão social, protecção social, cuidados de saúde e cuidados de longa duração ou continuados.

Esta revisão baseou-se fundamentalmente na constatação de desfasamentos entre os objectivos comuns europeus e a concretização das políticas, o que significava que o reforço do processo deveria avançar para além da identificação de grandes princípios e objectivos e concentrar-se na eficácia das políticas. Por outro lado, veio reclamar a necessidade de aprofundar a dimensão social da Estratégia de Lisboa revista, garantindo a coerência e o reforço mútuo entre os objectivos de crescimento e emprego e os da coesão social.

$\mathrm{Na}$ sequência deste processo de racionalização, foi proposto um conjunto de novos Objectivos Comuns, adoptados no Concelho Europeu da Primavera de 2006, em matéria de protecção social e inclusão social, considerando três objectivos transversais: (a) Promover a coesão social e a igualdade de oportunidades para todos, através de políticas de inclusão social e sistemas de protecção social adequados, acessíveis, financeiramente viáveis, adaptáveis e eficientes.

(b) Interagir de perto com os objectivos de maior crescimento económico e mais e melhores empregos fixados em Lisboa e com a estratégia de desenvolvimento sustentável da UE.

(c) Reforçar a governação, a transparência e a participação dos agentes relevantes na concepção, aplicação e acompanhamento das políticas.

Além destes três objectivos referidos que enquadram globalmente as três vertentes do MAC - inclusão social, pensões, cuidados de saúde e cuidados de longa duração ou continuados - foram ainda definidos três objectivos específicos para cada uma destas vertentes e que constituem a base dos Relatórios Nacionais de Estratégia para a Protecção Social e a Inclusão Social (2006-2008).

Explicitam-se, em seguida, os objectivos comuns de inclusão social, aos quais os PNAI 2006-2008 respondem:

(d) Garantir o acesso de todos aos recursos, direitos e serviços sociais básicos, necessários à participação na sociedade, ao mesmo tempo que se encontram respostas para formas extremas de exclusão e se combatem todas as discriminações conducentes à exclusão.

(e) Garantir a inclusão social activa de todos, através da promoção da participação no mercado de trabalho e do combate à pobreza e à exclusão das pessoas e dos grupos mais marginalizados.

(f) Garantir que as políticas de inclusão social são bem coordenadas e contam com o envolvimento de todos os níveis do governo e agentes pertinentes (incluindo as pessoas que vivem na pobreza), que são eficientes e integradas em todas as políticas públicas relevantes, designadamente as políticas económicas e orçamentais, de educação e

\footnotetext{
${ }^{3}$ In L'Agenda Social 2005-2010 - Une Europe Sociale dans l'économie mondiale; Des emplois et de nouvelles chances pour tous, Emploi \& affaires sociales, Comission Européenne.

4 Apresentado na Comunicação da Comissão "Trabalhar em conjunto, trabalhar melhor: Um novo enquadramento para o método aberto de coordenação aplicado às políticas de protecção social e inclusão social na União Europeia, Bruxelas, COM (2005) 706 final de 22 de Dezembro de 2005.
} 
formação e os programas dos fundos estruturais (nomeadamente o FSE), e que têm em conta a perspectiva da igualdade entre homens e mulheres.

Contudo, o já referido desfasamento entre os objectivos comuns europeus e a implementação de políticas permitiu indiciar que, quer a estratégia europeia, quer as estratégias nacionais de combate à pobreza e à exclusão social e a implementação das respectivas políticas, não conseguem produzir efeitos sem uma forte dimensão de compromisso político, empenhamento e acção de todos os actores relevantes aos diferentes níveis nacionais regionais e locais de cada Estado-Membro.

Apesar das estratégias europeias e nacionais para a inclusão social serem desde o início implementadas territorialmente, pois é nos níveis territoriais e locais que a implementação de programas, projectos e políticas se efectua, na verdade, muitos dos actores regionais e locais ainda não as incorporaram nem as assumem como um compromisso político nos seus respectivos níveis de intervenção.

De acordo com as avaliações das duas primeiras rondas de PNAI, um dos principais desafios que se coloca neste âmbito é a necessidade dos Estados-Membros garantirem uma forte integração vertical e horizontal das políticas económicas, de emprego, de formação contínua, de protecção social, de saúde, de habitação, sociais e culturais, colocando na Agenda Política a preocupação com o combate à pobreza e à exclusão social. Tal perspectiva é essencial para concertar uma estratégia integrada que contribua para minimizar causas e impactos da pobreza e da exclusão social.

\section{Alguma (im)precisão de conceitos}

Como vem sendo referido, os PNAI têm-se centrado nos problemas e fenómenos de pobreza e de exclusão social, apelando inclusivamente à utilização de indicadores comuns a todos Estados-Membros (designados indicadores de coesão social) no sentido de assegurar a comparabilidade em termos do diagnóstico social que é necessário efectuar como base de sustentação das Estratégias de Inclusão propostas.

Desde 2000 que a Comissão Europeia (CE) vem produzindo documentos orientadores quer sobre o MAC, quer sobre as directrizes comuns de base a partir das quais devem ser efectuados os respectivos Planos. Contudo, os conceitos de pobreza, exclusão social e inclusão social, foram sendo utilizados sem uma definição concreta e clara, que constitui-se a referência europeia, até 2003. O que significou que a primeira e a segunda gerações de Planos foram construídos em torno de quatro objectivos comuns de inclusão social, pressupondo uma utilização de tais conceitos, de forma mais operativa, à luz dos enunciados dos próprios objectivos.

Portanto, esta área foi-se pautando por alguma imprecisão, e até confusão, no que respeita a conceitos que se reportam a realidades e a fenómenos sociais que são distintos e complexos.

Só no Relatório Conjunto sobre a Inclusão Social apresentado no final de 2003 (COM 2003, 773 final), após entrega à Comissão Europeia da segunda geração de Planos, surgiram as primeiras definições dos conceitos de pobreza, exclusão social e inclusão social.

No referido Relatório a CE propôs que os Estados-Membros considerassem as seguintes definições ${ }^{5}$ :

"Pauvreté: une personne est considérée comme vivant dans la pauvreté si son revenu et ses ressources sont insuffisants au point de l'empêcher d'avoir un niveau de vie considéré comme acceptable pour la société dans laquelle il vit. En raison de la pauvreté, cette personne peut se trouver défavorisée de multiples manières: chômage, faible revenu, inconfort du logement, soins de santé inadéquats et obstacles à son accès à l'apprentissage tout au long de la vie, à la culture, au sport et aux loisirs. Elle est souvent marginalisée et exclue de la participation aux activités (économiques, sociales et culturelles) qui sont la norme pour les autres personnes, et son accès aux droits fondamentaux peut être restreint.

Exclusion sociale: l'exclusion sociale est un processus par lequel certaines personnes sont repoussées à la périphérie de la société. Elle les empêche de

\footnotetext{
${ }^{5}$ Estas definições destinam-se a completar e reforçar a compreensão dos termos de pobreza e de exclusão social de acordo com os objectivos e os indicadores comuns que suportam o MAC. E claro que seria interessante confrontar e discutir estes conceitos propostos com outros preconizados por vários autores, no sentido de observar que complementaridades e divergências numa problematização dos fenómenos que pudesse servir o avanço do conhecimento, no entanto, não é este o espaço pertinente para o fazer.
} 
participer pleinement à la vie sociale en raison de leur pauvreté, d'un manque de compétences de base et de possibilités d'apprentissage tout au long de la vie ou d'une discrimination. Ce processus les éloigne dés possibilités d'embauche, de revenu et d'éducation ainsi que des activités et des réseaux sociaux et communautaires. Ces personnes ont un accès très restreint au pouvoir et aux organismes de décision et se sentent donc souvent impuissantes et incapables d'influer sur les décisions qui affectent leur vie quotidienne.

Inclusion sociale: l'inclusion sociale est un processus qui garantit que les personnes en danger de pauvreté et d'exclusion sociale obtiennent les possibilités et les ressources nécessaires pour participer pleinement à la vie économique, sociale et culturelle, et qu'elles jouissent d'un niveau de vie et de bien-être considéré comme normal pour la société dans laquelle ils vivent. L'inclusion sociale leur garantit une meilleure participation aux processus de prise de décision qui affectent leur vie et un meilleur accès à leurs droits fondamentaux ${ }^{6}$.

Cadre général les articles 136 et 137 du traité d'Amsterdam donnent mission à la Communauté de jouer un rôle actif pour appuyer et compléter les activités des États membres en matière de lutte contre l'exclusion sociale. En ce sens, le Conseil européen de Lisbonne de mars 2000 a reconnu la nécessité de donner un élan décisif à l'élimination de la pauvreté d'ici 2010."”

Após as revisões efectuadas das quais se deu conta brevemente, os documentos orientadores mais recentes não fazem referência ou introduzem alterações às definições propostas. Pode ainda dizer-se que não deixa de ser curioso o facto de tais definições conceptuais terem surgido já depois de realizadas duas gerações de Planos, facto que permite colocar algumas questões: não teria sido importante uma discussão generalizada entre os diversos Estados-Membros para atingirem um consenso possível logo no início do processo, mesmo reconhecendo que as realidades sociais e os fenómenos de pobreza e exclusão social possuem diferentes configurações nos 27 Países da UE? Será ou não crucial que todos os Estados-Membros possuam semelhantes entendimentos relativamente aos conceitos em questão?

\section{Velhos problemas, novas configurações - alguns traços de diagnóstico ${ }^{8}$}

A que realidades sociais concretas se referem os conceitos antes definidos? Ainda que os indicadores quantitativos possam esconder dinâmicas difíceis de explicitar, eles permitem observar alguns dos principais traços caracterizadores dos fenómenos de pobreza e exclusão social em Portugal e, sempre que possível, da UE.

\section{Situações de pobreza}

Relativamente aos indicadores existentes, observava-se que, em 2004, cerca de $21 \%$ da população portuguesa vivia abaixo do limiar de pobreza, enquanto na UE25 a taxa era de $16 \%$. Registou-se uma ligeira melhoria desta taxa ao longo do período 1995-2003 (19\%, neste último ano), certamente em consequência da implementação de um conjunto de medidas, programas e metodologias de intervenção considerados mais activos.

Mas o risco de pobreza possui variações entre sexos, tornando evidente uma maior incidência de mulheres com baixos rendimentos o que, à semelhança da generalidade dos países europeus, conduz a uma certa "feminização da pobreza". Em Portugal, eram 22\% as mulheres que se encontravam em situação de pobreza, contra $20 \%$ dos homens (2004), e a manifestarem um risco de pobreza mais acentuado desde $1995^{10}$.

A persistência deste fenómeno era também visível, já que cerca de $15 \%$ da população portuguesa vivia abaixo do limiar de pobreza em 2001, e em pelo menos nos dois dos três anos precedentes $^{11 .}$, valor que diminuiu cerca de $4 \%$ no caso da população em idade activa, na mesma data.

\footnotetext{
6 Tais como se encontram definidos na Carta dos Direitos Fundamentais da União Europeia.

7 Ver Rapport Conjoint sur L'Inclusion Sociale, 2004, Sécurité sociale et insertion sociale, Comission Européenne, Direction Générale de L'Emploi et des Affaires Sociales, Unité E.2, p. 11, in http://ec.europa.eu/employment_social/social_inclusion/docs/ final joint inclusion report 2003 fr.pdf

Este Programa de Acção Comunitário Contra Exclusão Social esteve em vigor entre 2002 e 2006, tendo sido substituído, a partir de 2007 pelo PROGRESS.

${ }^{8}$ Os traços de diagnóstico apresentados encontram-se mais desenvolvidos no Plano Nacional de Acção para a Inclusão 2006-2008, MTSS, 2006. Coordenadora: Fernanda Rodrigues; Equipa Técnica de Apoio à Coordenação: Alexandra Amorim, Alda Gonçalves, Gisela Matos, Florbela Guerra e Rita Fernandes.

9 Eurostat, SILC.

${ }^{10}$ Eurostat, SILC.

${ }^{11}$ Eurostat, ECHP.
} 
A persistência deste tipo de situações parece resultar de uma correlação significativa entre o processo de desenvolvimento e a desigualdade, pois o grau de desigualdade na distribuição dos rendimentos mantém-se o mais elevado da UE. A proporção do rendimento recebida pelos $20 \%$ de pessoas com maiores rendimentos era 7,2 vezes superior à recebida pelos $20 \%$ de indivíduos com menores rendimentos, comparativamente a $4,8 \%$ na EU (em 2004) ${ }^{12}$. Por outro lado, cerca de 10,9\% de trabalhadores por conta de outrém estavam abaixo da linha de baixo salário, ou seja, possuíam 2/3 do ganho ilíquido mensal mediano. Cerca de $16 \%$ dos que se encontravam nesta situação eram mulheres e apenas $7,5 \%$ homens ${ }^{13}$.

Contudo, os fenómenos de pobreza são multidimensionais, e uma análise na óptica da privação afigura-se fundamental para melhor conhecer as diversas dimensões do bem-estar dos indivíduos e das famílias. "Entendendo a privação como a dificuldade de acesso a um nível mínimo de bem-estar ${ }^{14}$, cerca de $18.7 \%$ das famílias portuguesas estava em situação de privação em 2001. As condições internas do alojamento, a posse de bens de conforto, a capacidade de satisfação das necessidades básicas e as redes de sociabilidade são os aspectos que maior peso têm na explicação do grau de privação para as famílias em risco de privação. Além disso, são as famílias com crianças, as famílias numerosas e as famílias de uma única pessoa idosa que revelam o maior risco de $\operatorname{privação~}^{15}$.

A incidência da pobreza monetária revela ainda que dois dos grupos mais vulneráveis às situações de pobreza eram, em $2004^{16}$, as crianças $(23 \%)$ e os idosos $(29 \%)$.

Prevalecem ainda outros riscos que escapam ao quantitativo, mas que interferem decisivamente no crescimento/desenvolvimento das crianças, nomeadamente a sua segurança, saúde, educação e formação, como sejam as situações de abandono e de negligência, os maus-tratos, a exposição a modelos de comportamento desviante, o trabalho infantil, entre outros.

A protecção social às famílias tem assumido um papel essencial na melhoria do bem-estar das crianças, embora ainda insuficiente no combate à diversidade dos riscos. As próprias famílias, sobretudo as mais jovens, enfrentam actualmente dificuldades na conciliação entre a actividade profissional e os cuidados a prestar aos filhos, entre outras exigências que reclamam serviços e respostas sociais que possam, de forma mais eficaz, assegurar o seu bem-estar.

Como já se referiu, a população idosa era o grupo populacional que vivia em maior risco de pobreza, já que $29 \%$ viviam em risco de pobreza (30\% eram mulheres e 29\% homens) contra $21 \%$ da população total (2004) ${ }^{17}$.

A condição de pessoa reformada era, em 2004, reveladora de um risco de pobreza mais elevado (26\%) em comparação com os indivíduos trabalhadores (13\%). Em 2001, cerca de 66\% das pessoas idosas tinham rendimentos mensais inferiores à média nacional ${ }^{18}$. Apesar da melhoria do sistema de segurança social e, especialmente, do sistema de pensões, desde a segunda metade de 1990 continuam a verificar-se situações de grande vulnerabilidade, ou seja, de idosos a viverem com pensões muito baixas.

Acresce a esta vulnerabilidade outras, como a perda de autonomia, isolamento social, más condições habitacionais e, muitas vezes, um difícil acesso a serviços de saúde e/ou de apoio social.

Alguns dados existentes para $2000^{19}$, permitiam observar que a pobreza e a exclusão social se distribuíam de forma assimétrica no território nacional: as Regiões Autónomas evidenciavam uma maior incidência de pobreza monetária (cerca de $33 \%$ ), enquanto no Continente revelavam-se incidências mais elevadas no Algarve (25\%) e no Alentejo (22\%). Observava-se ainda que eram as

\footnotetext{
12 Eurostat, SILC.

${ }^{13}$ Cálculos efectuados pela DGEEP/MTSS com base nos Quadros de Pessoal do MTSS.

14 Esse nível mínimo de bem-estar diz respeito a um conjunto de aspectos relacionados com as condições de alojamento, bens de conforto, necessidades básicas, capacidade financeira, redes de sociabilidade, mercado de trabalho, educação e formação.

15 Cálculos efectuados pela DGEEP/MTSS com base no PEADP do INE, patentes no PNAI 2006-2008, MTSS, pp. 10-11.

16 Eurostat, SILC.

17 Eurostat, SILC.

${ }^{18}$ Cálculos efectuados pela DGEEP/MTSS com base no PEADP do INE, patentes no PNAI 2006-2008, p. 12.

19 Cálculos efectuados pela DGEEP/MTSS com base no Inquérito aos Orçamentos Familiares do Instituto Nacional de Estatística no âmbito do projecto "Medidas de Pobreza e Exclusão Social", patente no PNAI 2006-2008, MTSS, p. 13.
} 
zonas rurais as que se encontravam sujeitas a um risco de pobreza superior (33\%) comparado com as zonas urbanas $(16 \%)$.

De facto, as opções de desenvolvimento tenderam a acentuar clivagens entre as regiões rurais periféricas e regiões litorais, com reflexos numa grande concentração populacional no litoral, nomeadamente nas Áreas Metropolitanas, e uma consequente desertificação demográfica das primeiras. As inovações e modernizações dos mais diversos sectores têm-se concentrado sobretudo em cidades e vilas de média dimensão, enfraquecendo assim os territórios rurais confrontados com maior isolamento, escassez de investimentos produtivos, envelhecimento populacional e outras condições de vulnerabilidade.

Importa também referir a pobreza nas áreas urbanas e peri-urbanas, que se torna visível pelos fortes contrastes de concentrações populacionais em territórios estigmatizados por situações de exclusão e reprodutores de situações de pobreza persistente. Tratam-se, geralmente, de bairros clandestinos e/ou de casas abarracadas, de bairros de habitação social ou bairros antigos e degradados das cidades, cujo perfil populacional se caracteriza por baixos recursos económicos, baixas qualificações escolares e profissionais, precariedade de emprego, redes de marginalidade, mercados paralelos, dependências aditivas, entre outros.

\section{Protecção social e acesso a equipamentos}

Relativamente ao sistema de protecção social nacional, deve referir-se que se tem registado um crescimento gradual das despesas com a protecção social, a par com um aumento das situações e riscos cobertos, fazendo com que mais pessoas acedam às prestações, aos serviços e aos equipamentos sociais. Assim, a despesa total em protecção social traduz um esforço de convergência com a média da UE. Portugal gastava em protecção social 22,6\% em 2003 (contra 19,3\% em 1995).

As despesas com a população idosa representavam a maior fatia do conjunto das despesas em protecção social, seguindo-se a despesa com a doença e cuidados de saúde (respectivamente 8,9\% e $6,5 \%$ do PIB, dados de 2003) ${ }^{20}$.

Este esforço demonstra efeitos positivos, nomeadamente na redução das taxas de pobreza. Sem o efeito destas transferências sociais (exceptuando as pensões), a população em risco de pobreza monetária teria sido $27 \%$, por relação a $26 \%$ na UE25, em 2004. O risco de pobreza das crianças e dos idosos seria, respectivamente, de $32 \%$ e $34 \%{ }^{21}$.

Contudo, para que as transferências sociais monetárias sejam mais eficazes no combate à pobreza, devem ser acompanhadas de serviços e equipamentos que consigam responder às necessidades dos indivíduos e famílias.

Entre 1998-2004, o número de equipamentos sociais em funcionamento aumentou $31,1 \%$ (cerca de 300 equipamentos/ano) ${ }^{22}$. A área que revelou maior crescimento foi a relativa à população idosa (41\%), seguindo-se a de reabilitação e integração das pessoas com deficiência $(29,4 \%)$, família e comunidade $(28,8 \%)$ e infância e juventude (26,5\%). Assim, em 2004 existiam 4245 equipamentos com capacidade para 196266 crianças e jovens, 474 equipamentos com oferta de lugares para 14 634 pessoas com deficiência e 5420 com vagas para 187856 pessoas idosas ${ }^{23}$.

A concentração dos equipamentos tem acompanhado o padrão de distribuição da própria população no território, verificando-se maior densidade dos mesmos nas áreas metropolitanas de Lisboa e Porto e em toda a faixa litoral a norte da Península de Setúbal, bem como nos concelhos sede de Distrito.

\section{Emprego e desemprego}

As condições macroeconómicas globais possuem consequências desfavoráveis ao nível dos fenómenos de pobreza e exclusão social e Portugal vem-se ressentindo de tais condições.

Relativamente ao emprego, observa-se alguma estabilidade com as taxas globais de emprego acima das metas fixadas para a UE, embora se tenha registado uma estagnação do emprego e um aumento do

\footnotetext{
${ }^{20}$ SESPROS, Eurostat.

${ }^{21}$ Eurostat, SILC.

22 DGEEP, Carta Social, Rede de Serviços e Equipamentos Sociais, 2004.

${ }^{23}$ Idem.
} 
desemprego. Em 2005, ainda que a população activa tenha crescido 1\%, o emprego estacionou $(0 \%)$ e a taxa de desemprego passou de $6,7 \%$, em 2004 (5,9\% homens; $7,6 \%$ mulheres) para 7,6\%, em 2005 (6,7\% homens; 8,6\% mulheres) e a dos jovens aumentou de $15,3 \%$ para $16,1 \%$ (13,6\% de rapazes em 2004 e 2005 e 17,7\% e 19,1\% de raparigas em 2004 e 2005, respectivamente). A taxa de emprego global $(67,5 \%)$ registou um valor inferior ao de $2004(-0,3 \%)^{24}$, situando-se, contudo, acima da meta estabelecida pela Cimeira de Estocolmo para 2005 (67\%) e da Europa Comunitária $(63,8 \%)$.

A taxa de emprego feminina $(61,7 \%)$ manteve-se estável relativamente ao ano anterior e a dos trabalhadores dos 55 a 64 anos (50,5\%) aumentou ligeiramente, por referência a $2004(0,2 \%)$, ambas acima das metas estabelecidas para 2010 pelas Cimeiras de Lisboa e Estocolmo (respectivamente $60 \%$ mulheres; $50 \%$ para os trabalhadores dos 55 a 64 anos). 0 emprego dos jovens entre os 15 e os 24 anos foi o que sofreu maior redução $(-1,0 \%) \mathrm{em}$ relação a 2004, comparativamente à taxa registada na UE25, que se manteve (36,8\%).

Por seu lado, a taxa de desemprego de longa duração (3,7\%, em 2005) aumentou face a 2004 $(0,7 \%)$, com o DLD a representar 48,2\% do desemprego total $(44,3 \% \text {. em 2004) })^{25}$. A taxa feminina $(4,2 \%)$ aumentou $0,8 \%$ em relação ao ano anterior e o DLD feminino representava 48,8\% do desemprego total (44,9\% em 2004). Traço reforçador da vulnerabilidade das mulheres às situações de precariedade e desemprego.

Outros grupos que enfrentam particulares vulnerabilidades em termos de participação no mercado de trabalho são o os jovens entre 15 e 24 anos, cuja taxa de desemprego aumentou de 9,4\% (em 2001) para $16,1 \%$ (em 2005) ${ }^{26}$ e o dos trabalhadores mais idosos (entre 55 e 64 anos), que registava uma taxa de $3,2 \%$ em 2001 e que praticamente duplicou em $2005(6,2 \%)^{27}$, os dois em geral com baixas habilitações e qualificações profissionais, handicapes que dificultam a inserção e participação no mercado de emprego.

\section{Educação e formação}

Torna-se então perceptível que a escolarização e as qualificações da população são elementos estruturantes fundamentais, quer para a compreensão de fenómenos de pobreza e exclusão social, quer para a inclusão dos grupos sociais mais vulneráveis.

Nos últimos trinta anos tem-se observado uma expansão do sistema educativo e o alargamento da escolaridade obrigatória.

$\mathrm{O}$ ensino pré-escolar tem registado as mudanças mais significativas já que, em 2004, $79,9 \%$ das crianças de 4 anos frequentavam a educação pré-escolar (comparativamente a 85,8\% na UE), representando um crescimento de cerca de $47 \%$ face a $1995^{28}$.

Pode dizer-se que as taxas de escolarização subiram de forma significativa, observando-se que os jovens com 18 anos integrados no sistema educativo passou de $30 \%$ para $62 \%$ entre 1991 e $2001^{29}$. Contudo, Portugal mantém-se consideravelmente abaixo da média dos países da UE25.

Observaram-se também progressos nos jovens de 20-24 anos que completaram pelo menos o nível de ensino secundário (ISCED 3), tendo passado de 44,2\%, em 2002 para 49\%, em 2004, embora ainda distantes dos 76,7\% da UE25 na mesma data. Também a taxa de saída escolar precoce baixou de 45,1\%, em 2002 para 39,4\%, em $2004^{30}$ e para $38,6 \%$, em $2005^{31}$. Valores ainda bastante acima das médias da UE25 (15,7\% em 2004 e 15,2\% em 2005). Quanto à taxa de frequência do ensino superior, esta era de 29,9\%, em 2003.

No entanto, em 2005, 38,6\% de jovens de 18-24 anos abandonaram o sistema de ensino com a escolaridade obrigatória (ISCED 2) ou menos, e não frequentaram qualquer acção de educação ou formação (46,7\% rapazes e $30,1 \%$ raparigas). $\mathrm{Na}$ UE25, este valor era de 15,2\% (17,3\% rapazes e $13,1 \%$ raparigas $)^{32}$, o que mais uma vez coloca

\footnotetext{
24 INE, Inquérito ao Emprego.

25 Idem.

${ }^{26}$ INE, Inquérito ao Emprego.

27 Idem.

${ }^{28}$ Eurostat, Education Statistics.

29 INE, Censos.

${ }^{30}$ Com registo de um maior peso para os rapazes $(47,9 \%)$ do que para as raparigas $(30,6 \%)$.

31 LFS, Eurostat.

32 LFS, Eurostat.
} 
Portugal numa posição desfavorável comparativamente aos restantes Estados-Membros.

Refira-se ainda que, em 2005, 73,8\% da população desempregada com idades entre os 15$-64 \operatorname{anos}(77,9 \%$ de homens e 70,0\% de mulheres), possuía níveis de escolaridade até ao ensino básico (3. ${ }^{\circ}$ ciclo) e 15,4\% tinham o Ensino Secundário. Relativamente aos DLD verificava-se que, na mesma data, $4 \%$ não possuía qualquer nível de escolaridade; $31.7 \%$ tinha apenas o $1 .^{\circ}$ Ciclo EB; $21.1 \%$ o $2 .^{\circ}$ Ciclo EB e $22.1 \%$ possuía o $3 .^{\circ}$ Ciclo $\mathrm{EB}^{33}$.

Por seu lado, os níveis de escolaridade da população empregada (15-64 anos), embora globalmente baixos, eram um pouco mais elevados que os da população desempregada. Assim, em 2005, 72,1\% possuíam um nível de escolaridade até ao $3 .^{\circ}$ Ciclo $\operatorname{EB}(76,2 \%$ de homens e $67,3 \%$ de mulheres $)^{34}$.

Observam-se assim riscos de clivagens entre os que têm e os que não tem acesso à educação/ /formação e à aprendizagem ao longo da vida, com consequências ao nível do acesso ao emprego.

Estes são apenas alguns dos traços de diagnóstico que devem preocupar e mobilizar a responsabilidade colectiva de todos os actores relevantes no combate à pobreza e à exclusão social e constituir a razão de ser da estratégia nacional de inclusão social, expressa no Plano Nacional de Acção para a Inclusão.

\section{Breve análise dos planos nacionais de acção para a inclusão}

\section{Dimensões globais de análise}

Após uma breve descrição do contexto europeu de surgimento e impulso para a concepção e implementação destes Planos e dos principais traços de diagnóstico relativos à pobreza e exclusão, que invocam algumas das razões que os suportam independentemente da existência de um processo europeu de inclusão social, traça-se em seguida uma breve panorâmica do percurso dos mesmos ao nível nacional e de alguns dos desafios que se colocam.

Alguns destes desafios passam por tornar legível qual a mais valia que os Planos trazem em termos de respostas concretas às situações problemáticas em questão e, também, por perceber se a forma como continuam a ser construídos se afigura como a mais adequada...

Comece-se então por uma proposta analítica dos diferentes Planos Nacionais de Acção para a Inclusão o que pressupõe equacionar algumas das dimensões de análise mais relevantes neste âmbito e que podem centrar-se, por exemplo, nas propostas pela equipa externa que efectuou a avaliação do Programa de Acção Comunitário de Combate à Exclusão Social ${ }^{35}$ para a Comissão Europeia:

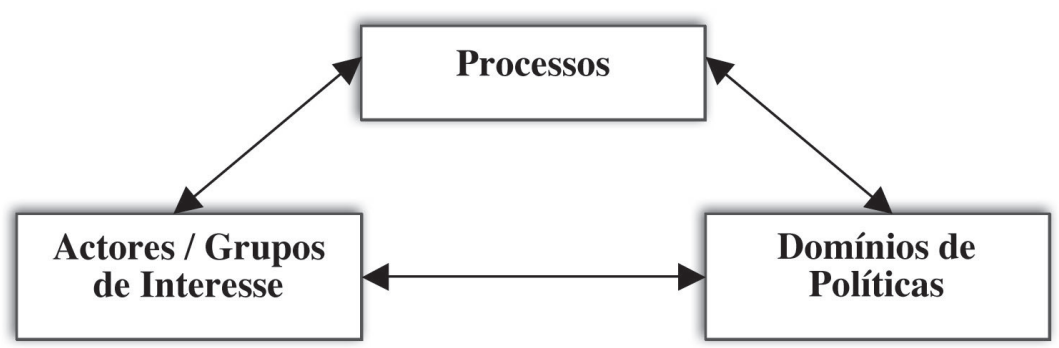

Figura 1. Dimensões Globais de Análise

Fonte: Evaluation of the Programme of Community Action to encourage co-operation between Member States to combat social exclusion, Travistock Institute, Engender and ECWS/ European Commission Social Inclusion Unit/ E2, p. 23 (Documento preliminar, não publicado).

\footnotetext{
33 INE, Inquérito ao Emprego.

${ }^{34}$ INE, Inquérito ao Emprego.

35 Abraham, Frances; Child, Camilla; Hadjivassiliou, Kari; Sandamas, Claire; King, Sadie; Braithwaite, Mary; Fries, Renate; Wuiame, Nathalie; Danau, Dominique, Evaluation of the Programme of Community Action to encourage co-operation between Member States to combat social exclusion, Travistock Institute, Engender and ECWS/European Commission Social Inclusion Unit/E2, p. 23 (Documento preliminar, não publicado).
} 
Os autores propuseram três dimensões relevantes que se mostram também importantes na análise dos próprios Planos, na medida em que estes se inserem em processos, devem envolver actores relevantes (governamentais e não governamentais) em todas as suas fases (concepção, implementação, monitorização e avaliação) e consignar políticas que correspondam às soluções relevantes para os complexos problemas de pobreza e exclusão equacionados, pressupondo uma ideia de mudança.

O esquema permite ainda perceber a importância da inter-relação entre as três dimensões globais de análise, para a implementação das estratégias de inclusão.

Este tipo de análise aplicada às três gerações de Planos até agora existentes permite perceber algumas questões interessantes. Observe-se o quadro das páginas seguintes: 


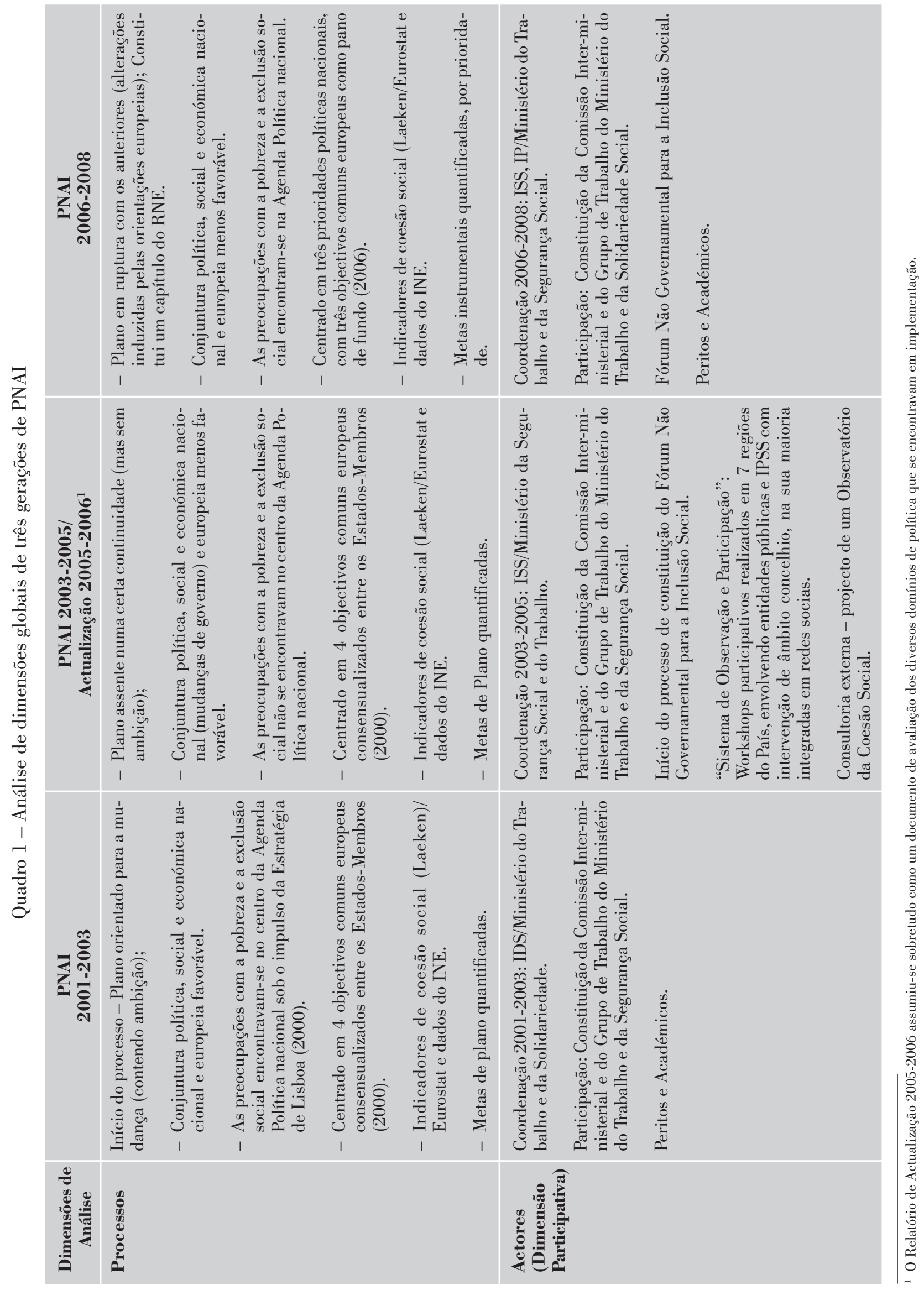




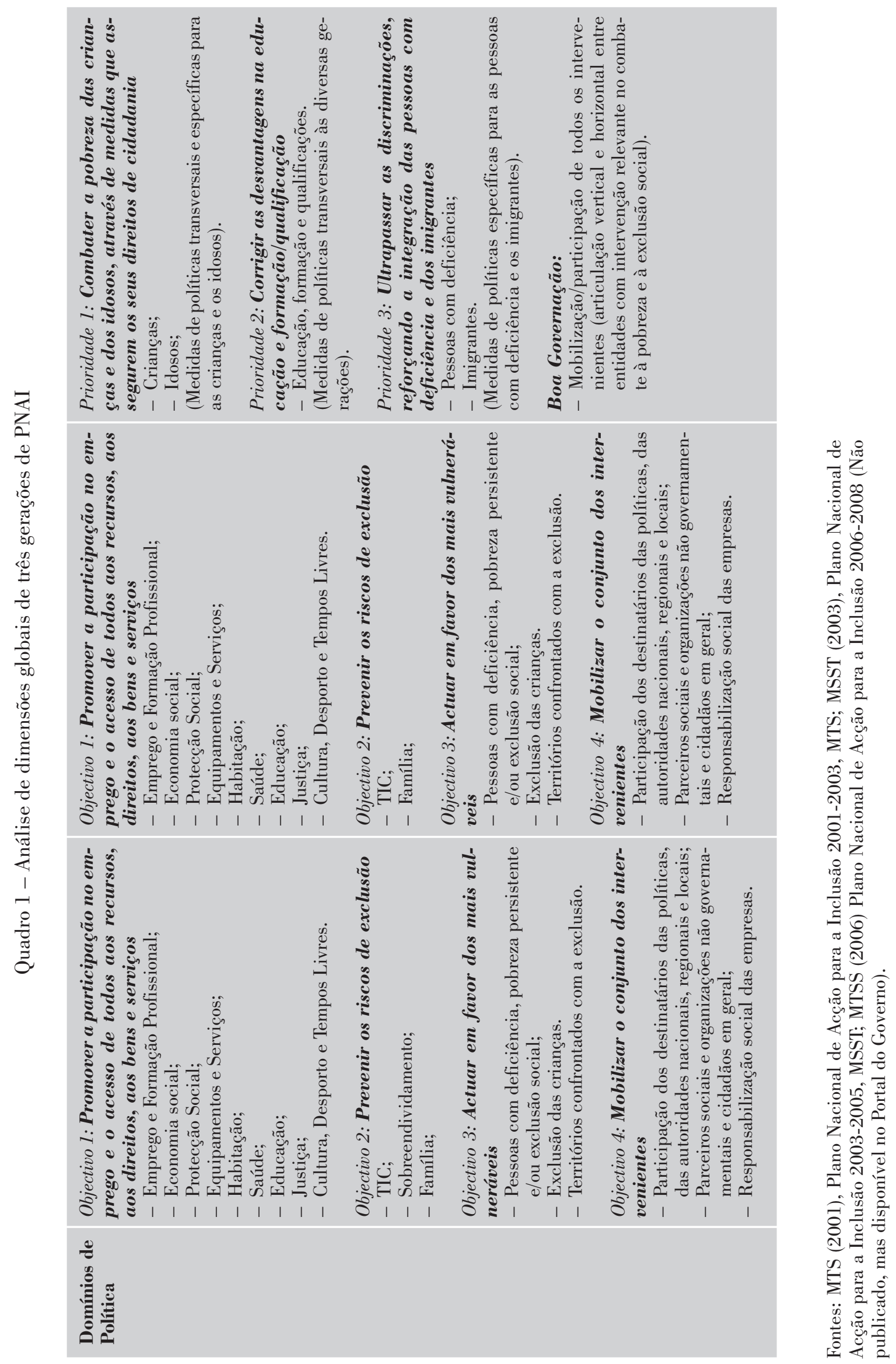


Em traços gerais, em relação à dimensão "processos", importa assinalar o seguinte:

- Uma relativa continuidade entre o primeiro e o segundo Planos, que deve ser lida a dois níveis: i) nível europeu, na medida em que os documentos da CE continham orientações semelhantes; os objectivos comuns mantiveram-se, assim como os indicadores de Laeken (coesão social); observava-se uma conjuntura política, económica e social europeia mais favorável no decorrer da primeira geração de Planos, tal como as preocupações com a pobreza e exclusão social. ii) Nível nacional, o primeiro Plano encontrou motivação numa conjuntura política, económica e social favorável, na qual foi possível dar destaque às preocupações com a pobreza e a exclusão social e foram concebidas e implementadas algumas políticas e programas mais inovadores e activos com um objectivo de mudança, perceptível na própria ambição das metas. Contudo, as alterações políticas ${ }^{36}$ (incluindo as alterações em termos de Coordenação) que se verificaram e sob as quais foi elaborado o segundo Plano, que prosseguiu numa linha de relativa continuidade com o anterior, tiveram repercussões assinaláveis, nomeadamente no que respeita aos compromissos políticos, observando-se que as preocupações com a pobreza e a exclusão social deixaram de constituir referência e as metas pouco ambiciosas do Plano eram demonstrativas desse facto.

- Em 2006, as orientações da CE mudaram, como já foi referido, sendo de alguma forma demonstrativas de uma conjuntura política e económica mais desfavoráveis à dimensão da inclusão e da coesão sociais. Assim, embora se possam assinalar referências a um processo revisto, mas capaz de integrar as lições aprendidas anteriormente, o que é facto é que se observou uma fractura na própria perspectiva de inclusão social. Enquanto as orientações anteriores preconizavam um PNAI integrador da multidimensionalidade dos problemas de pobreza e exclusão social, reclamando a existência de políticas integradas, numa dupla perspectiva, a reparadora e a preventiva e combinando uma intervenção simultaneamente por problemática e por grupos vulneráveis, as orientações actuais, embora teoricamente interessantes, mostram-se mais fragmentárias: o PNAI surge como um capítulo de um documento mais abrangente (o Relatório Nacional de Estratégia), a par com outros dois que antes se integravam nele (o sistema de protecção social e os cuidados continuados de saúde); ao centrarem-se em prioridades políticas nacionais, os Planos tornaram-se mais focalizados, nomeadamente em grupos vulneráveis e, em certa medida, menos integradores. Ao nível nacional, embora a pobreza e exclusão social apareçam como preocupação política, o que é facto é que a conjuntura económica de contenções orçamentais limita a capacidade de acção/ intervenção neste domínio.

Quanto à dimensão participativa, constata-se que no decurso do segundo Plano se registou uma considerável dinâmica de "actores" e um maior número de envolvidos, embora com menor compromisso político. Face a novas mudanças políticas algumas das dinâmicas que começaram por se esboçar perderam-se (p.e., os workshops participados realizados em 7 regiões do País, com entidades integradas em Redes Sociais locais e a proposta de um Observatório que se começava a configurar) e outra viu a sua participação reforçada no âmbito do PNAI 2006-2008 - o Fórum Não Governamental para a Inclusão Social.

No que respeita aos domínios de política, o quadro permite observar claramente as diferenças de abordagem dos dois primeiros Planos para o terceiro: das problemáticas para grupos vulneráveis específicos e portanto, a passagem para uma maior focalização, mas também para uma maior fragmentação face à multidimensionalidade dos problemas de pobreza e exclusão social. Esta fragmentação acabou por se tornar visível no equacionamento de metas instrumentais inspiradas nas próprias medidas de política.

No contexto destes domínios são, em geral, propostos os instrumentos e/ ou medidas de política

${ }^{36}$ Portugal teve três Governos entre 2002 e 2004. 
pelos diversos sectores representados (na Comissão Interministerial de Acompanhamento e no Grupo de Trabalho do MTSS) em resposta aos problemas diagnosticados e em consonância com os objectivos comuns e as respectivas prioridades. A maioria das soluções ou medidas propostas encontram-se já em curso quando os Planos são efectuados, na medida em que se enquadram necessariamente nos Programas dos Governos respectivos.

Um dos desafios importantes que se colocam hoje é o de conseguir que a importância da implementação, da monitorização e da avaliação das medidas, sejam amplamente reconhecidos aos diversos níveis regionais e locais, onde o trabalho das parcerias intersectoriais é imprescindível.

\section{Algumas reflexóes em torno da monitorização e avaliação}

A importância da monitorização e avaliação é consensual, pois trata-se de uma dimensão fundamental em todos os processos de planeamento, nomeadamente em intervenções de combate à pobreza e à exclusão social, para que seja possível, em cada momento, definir e reorientar o caminho mais eficaz e eficiente a seguir.

Contudo, verifica-se que uma das dificuldades mais prementes a resolver é justamente a da monitorização e avaliação das políticas sociais e, sobretudo, a medição dos seus impactos.

Também neste âmbito se verifica que a monitorização e a avaliação possuem dois níveis:

- Nível europeu, assente em indicadores estruturais, nos quais se incluem os de coesão social, cabendo à CE a tarefa de os facultar, após as respectivas actualizações que não têm sido tão céleres quanto seria desejável. Servem objectivos de diagnóstico e, simultaneamente, de avaliação. Passa pela elaboração de Relatórios Conjuntos de avaliação dos Planos de Inclusão, dando conta das estratégias de inclusão de todos os Estados-Membros e das suas potencialidades e fragilidades, com recomendações específicas a cada um. E passa ainda pela existência de uma "rede de consultores externos", ou seja, a CE contrata um perito independente $^{37}$ em cada Estado-Membro, responsável pela elaboração de relatórios semestrais de monitorização da implementação de políticas sociais, que constituem recursos complementares para a elaboração dos respectivos Relatórios Conjuntos.

- Nível nacional, embora desde o início deste processo (2001) até ao momento, sempre tenham sido previstos mecanismos de monitorização, consubstanciados numa matriz de indicadores de resultados das medidas de política e actualizáveis (anualmente) por intermédio de uma ficha de recolha de informação disponibilizada a cada Ministério/ /entidade responsável pela implementação das medidas no terreno, algumas dificuldades práticas têm constituído obstáculo a esta tarefa. Nesta matriz incluem-se também os indicadores de coesão social.

Relativamente a algumas das dificuldades pode dizer-se que se situam também a níveis diversos: de processo, dos actores/entidades e dos próprios indicadores.

- Ao nível do processo, incluindo neste âmbito o nível de governação, na medida em que a tomada de decisão se deve basear em informação continuamente actualizada, há questões complexas sobre as quais a reflexividade se deve deter para se poderem encontrar respostas: como compatibilizar a diversidade de informação proveniente da implementação de outros Planos que também se cruzam com a Inclusão? Como medir impactos de políticas no curto prazo (de dois em dois anos) de duração dos Planos?

- Quanto aos actores/Ministérios/entidades envolvidos, importa referir que algumas das dificuldades sentidas se prenderam com as mudanças políticas que têm ocorrido e que, desde logo, se reflectiram em alterações de Coordenação dos Planos e de novas nomeações em termos dos representantes que integram a Comissão de Acompanhamento Interministerial, pelo tempo de adaptação e os ajustamentos necessários.

- Relativamente aos próprios indicadores, colocam-se pelo menos duas ordens de questões: 1) a maioria dos indicadores

${ }^{37}$ No caso português, a Dr. ${ }^{\text {a }}$ Isabel Batista (CESIS) tem assumido, desde 2003, esta função. 
de Coesão Social não possuem desagregação regional e/ou local que permitam perceber as assimetrias territoriais; são insuficientes os indicadores para medir o fenómeno da pobreza, desigualdade e exclusão social especialmente ao nível regional e local, sendo também insuficientes os indicadores Coesão Social desagregados que permitam uma análise por grupos (nacionalidade, sexo, grupo etário, incapacidades $^{38}$.

2) Como compatibilizar a análise de resultados da implementação das políticas com uma análise dos indicadores de coesão social, para obter uma leitura sobre a a evolução das situações de pobreza e exclusão social e da coesão?

Pode dizer-se que, em termos nacionais, o processo se encontra em fase de aprofundamento e progresso para que a monitorização e a avaliação se afigurem mais coerentes. Importa articular e fazer convergir para os mesmos objectivos contextos institucionais diferentes e aprofundar a reflexividade sobre a própria utilidade dos procedimentos de monitorização e avaliação, nomeadamente no que respeita aos impactos das políticas públicas (Guibentif, 2005).

\section{Síntese final}

As estratégias delineadas no âmbito dos Planos pressupõem uma capacidade de mudança, em termos de inclusão e coesão social, em última instância, em termos da melhoria das condições e da qualidade de vida dos cidadãos, particularmente dos mais desfavorecidos.

Assim, importa que a estratégia preconizada tenha em consideração políticas quer integradas, quer sectoriais que reflictam uma preocupação em termos de impactos sobre a pobreza e a exclusão social, ou seja, que permitam implementar o mainstreaming da inclusão social com efeitos positivos, nomeadamente nas esferas e públicos de maiores vulnerabilidades.

A circulação de informação, a sensibilização da sociedade e a mobilização de todos os intervenientes relevantes são mecanismos decisivos para a implementação das medidas de política que corporizam as estratégias de inclusão social, quer ao nível europeu, quer aos níveis nacional, regional e local.

A monitorização/acompanhamento e avaliação devem ser aprofundados para se tornarem, cada vez mais, parte integrante dos processos de inclusão, tendo em consideração a complexidade das realidades sociais de partida e desafios já enunciados, alguns dos quais bem patentes no breve diagnóstico feito. Importa não esquecer que algumas polarizações continuam a demonstrar a importância de estratégias que contribuam decisivamente para a redução da pobreza e da exclusão, nomeadamente as questões económicas e demográficas.

As políticas socioeconómicas actuais têm que equacionar a importância e mais valia dessa redução por questões de cidadania e justiça social, de prosperidade económica e de fortalecimento da própria sociedade e da coesão social (EFILWC, 2006).

\footnotetext{
38 Algumas destas conclusões foram possíveis de retirar também a partir de um Projecto Transnacional em curso (designado Local Action Plans \& Regional Action Plans), no qual Portugal é um dos parceiros e cujo objectivo é justamente "experimentar" modalidades de concepção de Planos Regionais e/ou Planos Locais de Inclusão.
} 


\section{Bibliografia}

ABRAHAM, Frances; Child, Camilla; Hadjivassiliou, Kari; Sandamas, Claire; King, Sadie; Braithwaite, Mary; Fries, Renate; Wuiame, Nathalie; Danau, Dominique, 2006, Evaluation of the Programme of Community Action to encourage co-operation between Member States to combat social exclusion, Bruxelas, Travistock Institute, Engender and ECWS/ /European Commission Social Inclusion Unit/ E2, (Documento preliminar, não publicado).

CE, 2004, Rapport Conjoint sur L'Inclusion Sociale, Sécurité sociale et insertion sociale, Commission Européenne, Direction Générale de L'Emploi et des Affaires Sociales, Unité E.2, p.11, http://ec.europa.eu/employment_social/social_inclusion/docs/final_joint_inclusion_report_2003_fr.pdf.

CE, 2005, L'Agenda Social 2005-2010 - Une Europe Sociale dans l'économie mondiale; Des emplois et de nouvelles chances pour tous, Emploi \& affaires sociales, Bruxelas, Commission Européenne.

CE, 2005, Trabalhar em conjunto, trabalhar melhor: Um novo enquadramento para o método aberto de coordenação aplicado às políticas de protecção social e inclusão social na União
Europeia, Bruxelas, COM (2005) 706 final de 22 de Dezembro de 2005.

ESTIVILL, Jordi, 2003, Panorama de luta contra a exclusão social, Espanha, BIT/ STEP, P. v.

European Foundation for the Improvement of Living and Working Conditions (EFILWC), 2006, Competitive Europe Social Europe, Partners or Rivals? Dublin, Foundation Forum. www.eurofound.europa.eu

GUIBENTIF, Pierre, 2005, "Avaliação e Reflexividade - a Prática da Sociologia na Terceira Modernidade", Revista Cidades, Comunidades e Territórios, $\mathrm{n}^{\circ}{ }^{10}$, Lisboa, Centro de Estudos Territoriais, ISCTE, Junho. 2005.

MTS, 2001, Plano Nacional de Acção para a Inclusão 2001-2003, Lisboa, MTS.

MSST, 2003, Plano Nacional de Acção para a Inclusão 2003-2005, Lisboa, MSST.

MTSS, 2006, Plano Nacional de Acção para a Inclusão, 2006-2008, MTSS (Documento não publicado, mas acessível no Portal do Governo). 